\title{
Evaluation of functional outcome of intertrochanteric femur fractures treated with proximal femoral locking compression plate
}

\author{
Maruti Bhujangrao Lingayat, Pratik P. Rathod*
}

Department of Orthopaedics, Government Medical College and Hospital, Aurangabad, Maharashtra, India

Received: 21 July 2021

Revised: 04 August 2021

Accepted: 05 August 2021

\author{
*Correspondence: \\ Dr. Pratik P. Rathod, \\ E-mail: rathodpratik56@gmail.com
}

Copyright: (c) the author(s), publisher and licensee Medip Academy. This is an open-access article distributed under the terms of the Creative Commons Attribution Non-Commercial License, which permits unrestricted non-commercial use, distribution, and reproduction in any medium, provided the original work is properly cited.

\begin{abstract}
Background: The objective was to find out the clinical and functional outcome of intertrochanteric femur fractures treated with proximal femoral locking compression plate (PFLCP).

Methods: The study was conducted on patients who underwent fixation of intertrochanteric femur fractures with PFLCP in department of orthopedics, GMCH, Aurangabad from January 2020 to January 2021. The patients were assessed clinically and functionally using Harris hip score and radiological evaluation at three, six and nine months.

Results: At one year follow up, two patients had varus collapse, one had superficial infection and one had screw cut out. The mean Harris hip score at one month was 69.46 (52-76), at three months was 78.6 (58-88) and at nine months was 87.6 (64-96). The average operative time was 86.23 minutes (60-128 minutes), the average blood loss was 207.5 $\mathrm{ml}(170-250 \mathrm{ml})$ and the average time required for union was 15.16 weeks (10-24 weeks).

Conclusions: Intertrochanteric fractures treated with PFLCP provided a strong angular stable construct and showed satisfactory outcomes.
\end{abstract}

Keywords: Intertrochanteric fractures, Proximal femoral locking compression plate, Hip fractures, Osteoporotic bones

\section{INTRODUCTION}

The femur is surrounded by plenty of soft tissue envelope and is usually fractured due to high energy trauma in the young and with trivial trauma in the old. Without suitable precautions the fracture undergoes malunion, leading to varus and external rotation deformity at fracture site with shortening and limitation of hip movements. ${ }^{1}$ Conservative methods are now indicated only for patients who are medically unfit for surgery and those who refuse surgery. Taking all factors in consideration, surgery by internal fixation is the ideal choice. ${ }^{2}$ Factors determining the strength of fracture fixation depends on factors such as bone quality, fragment geometry, reduction and implant type and placement. ${ }^{3}$ Complications with dynamic hip screw include uncontrolled collapse and lag screw cut-out (with or without varus collapse), medialization of shaft, uncontrolled lateralization of proximal fragment. The problems associated with cephalo medullary nails include screw cut-out/blade cut-out (including $\mathrm{Z}$ effect and reverse $\mathrm{Z}$ effect), varus deformity, lateral wall blowout during reaming, difficult insertion in curved femurs, peri-implant fractures and implant breakage. ${ }^{4-6}$ Anatomically contoured locking plates (PFLCP) provide an angular stable construct and prevent screw cut-out and varus failure. These plates can also be used in severely osteoporotic bones and grossly comminuted fractures while maintaining the fracture biology.

\section{METHODS}

This was a prospective study, done under the guidelines of the ethical committee of the institution. A written, valid, informed consent was taken from all patients participating 
in the study. A total of thirty patients with intertrochanteric femur fractures were studied. All the cases were treated between January 2020 to January 2021 in department of orthopedics, GMCH, Aurangabad. All the patients who were brought to casualty and outpatient department with intertrochanteric fractures were selected for the study.

\section{Inclusion criteria}

Adults with intertrochanteric fractures, patients willing to give consent to participate in the study, patients with isolated intertrochanteric fractures confirmed on radiographs, patients with fractures less than two weeks old and patients who were medically fit for surgery were included in the study.

\section{Exclusion criteria}

Patients with pathological fractures, patients with compound fractures, pediatric age group patients, patients with old neglected fractures, patients medically unfit for surgery and patients not willing for surgical intervention were excluded from the study.

\section{Statistical software}

The statistical software SPSS version 24.0 was used for the analysis of data. Microsoft word and excel were used for generation of tables, graphs. The data was represented as percentages and mean with standard deviation.

\section{Implant details}

\section{PFLCP}
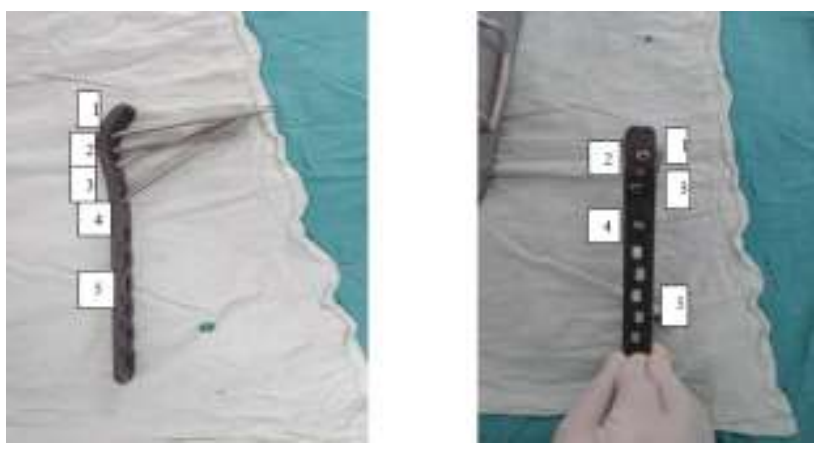

Figure 1: Proximal femoral locking compression plate of 6 holes length with (1) 95 degree $7.3 \mathrm{~mm}$ locking screw; (2) 95 degree 3.5 mm locking screw; (3) 120 degree $7.3 \mathrm{~mm}$ locking screw; (4) 133 degree $7.3 \mathrm{~mm}$ locking screw; (5) 4.5 mm locking screw hole.

The PFLCP was anatomically contoured which helped it to best fit the natural shape of proximal femur. The PFLCP was available in various sizes according to the need. The first proximal hole was a 95 degree hole, the second was a 120 degree hole and the third proximal hole was a 133 degree hole. There was an intermediate hole between the first and the second hole of 95 degree but of reduced diameter. The plate length was estimated from the preoperative radiographs of the injured as well as normal limb to estimate the length and varus,valgus angulation.

\section{Operative protocol}

All patients were given one dose of injectable third generation 30 minutes before surgery.

\section{Anesthesia}

The procedure was carried out under spinal or epidural anesthesia (with occasional general anesthesia as per indication).

\section{Position}

Patients were positioned supine on fracture table and were appropriately painted and draped. Reduction was achieved, maintained and confirmed under image intensifier paying special attention to medial and posterior cortex.

\section{Surgical procedure}

A $15 \mathrm{~cm}$ vertical incision was taken from tip of trochanter along the shaft of femur. Fascia lata was split in line with the incision and gluteus medius along with vastus lateralis were opened in line with the fibers. The fixed-angle guidewires were threaded to the proximal three holes of the plate and the plate was approximated to the proximal femur. First guidewire was inserted through the most proximal 95 degree hole, second through the 120 degree hole and third through the 133 degree hole making sure that the guidewires were in the center of the femoral head in anteroposterior and lateral views under the image intensifier. The screw lengths were measured using an indirect device over the guidewires and appropriate sized fully threaded screws $(7.3 \mathrm{~mm}$ for proximal three screws and $3.5 \mathrm{~mm}$ for a small hole between second and third screws) were inserted. Distal screw fixation was then done. After completion of procedure, a thorough was given with normal saline and antiseptic solution. Wound was closed in layers over a suction drain and an adequate sterile dressing was done.

\section{Postoperative care}

The patients were shifted to the postoperative wards after recovery from anesthesia. The patients were administered adequate analgesia and intravenous antibiotics for 5 days and were shifted to oral antibiotics henceforth. Prophylactically, in all patients, subcutaneous low molecular weight heparin (LMWH) was given for three consecutive days.

Passive and assisted active hip, knee and ankle mobilization was started on third postoperative day except for those having severe comminution and/or osteoporosis. 


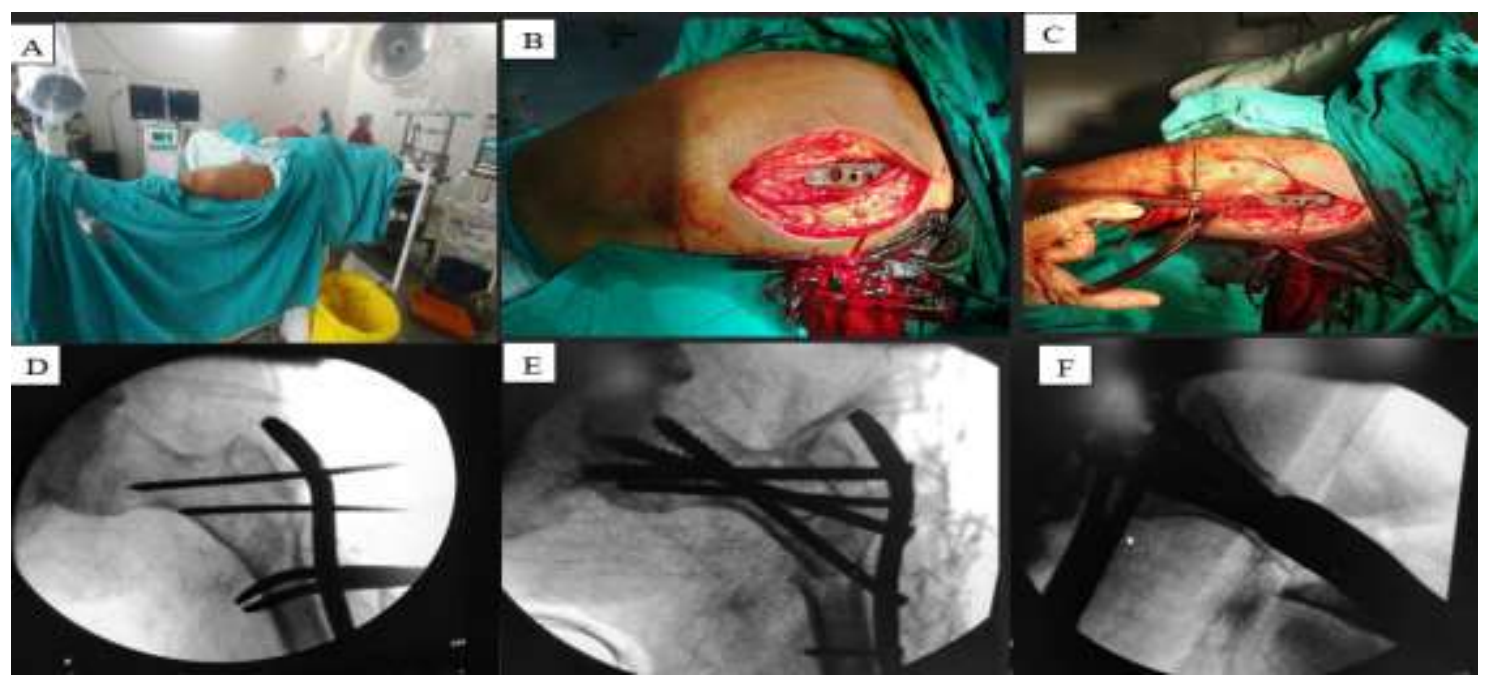

Figure 2: (A) Patient position on fracture table; (B) exposure and plate placement; (C) fracture temporary fixation with k-wires (surgical image); (D) image intensifier image of temporary fixation; (E) image intensifieranteroposterior view; $(F)$ image intensifier lateral views.

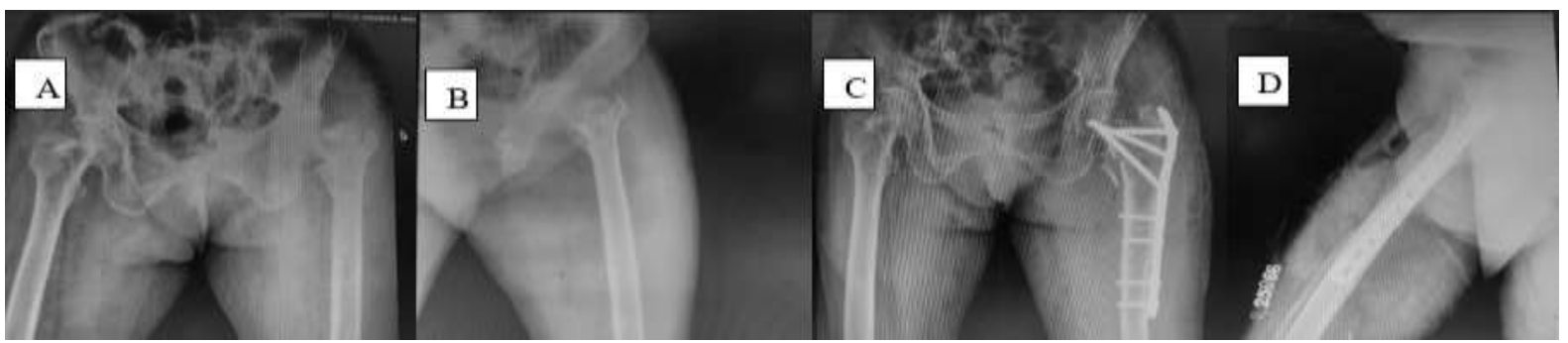

Figure 3: Case 1; X-rays; preoperative and immediate postoperative radiographs; (A) preoperative anteroposterior view; (B) pre-operative lateral view; (C) postoperative anteroposterior view; (D) postoperative lateral view.

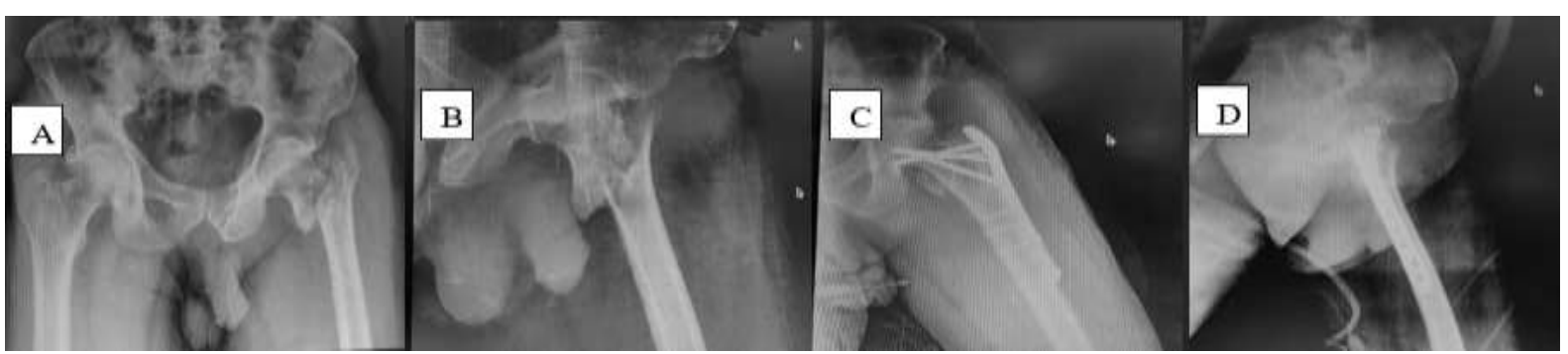

Figure 4: Case 2 X-rays; preoperative and immediate postoperative radiographs; (A) preoperative anteroposterior view; (B) preoperative lateral view; (C) postoperative anteroposterior view; (D) postoperative lateral view.

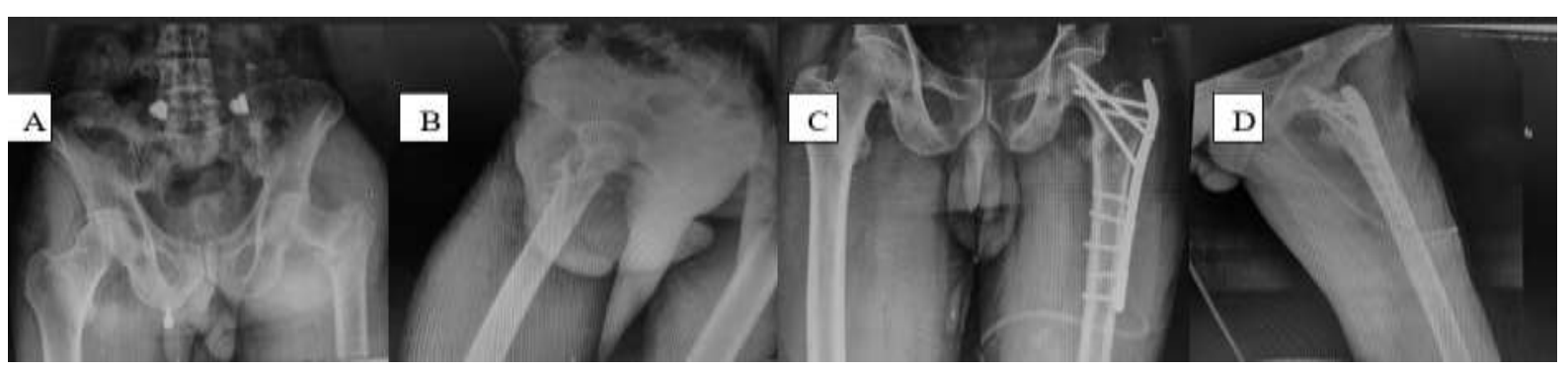

Figure 5: Case $3 \mathrm{X}$-rays; preoperative and immediate postoperative radiographs; (A) preoperative anteroposterior view; (B) preoperative lateral view; (C) postoperative anteroposterior view; (D) postoperative lateral view. 


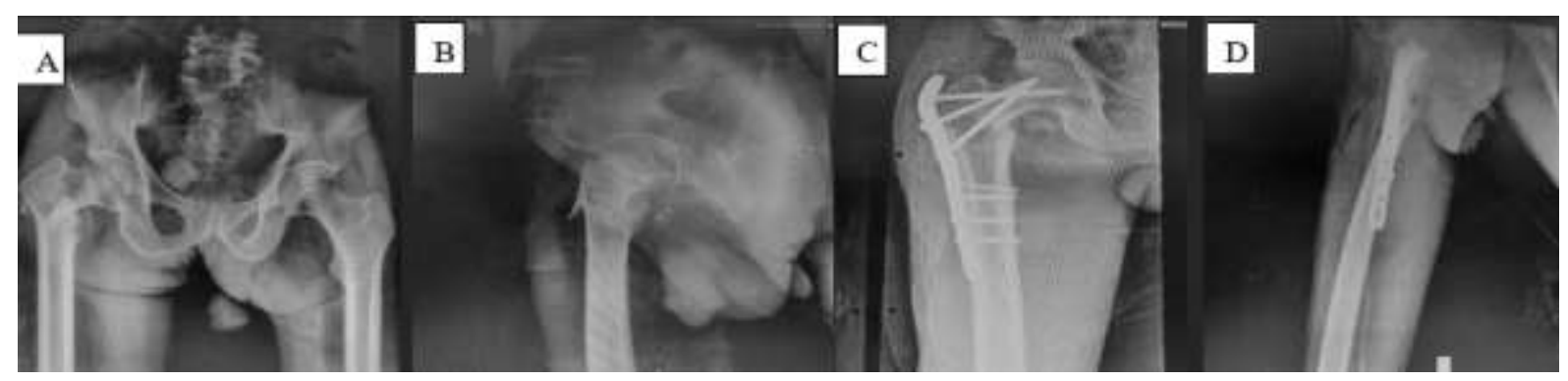

Figure 6: Case $4 \mathrm{X}$-rays; preoperative and immediate postoperative radiographs; (A) preoperative anteroposterior view; (B) preoperative lateral view; (C) postoperative anteroposterior view; (D) postoperative lateral view.

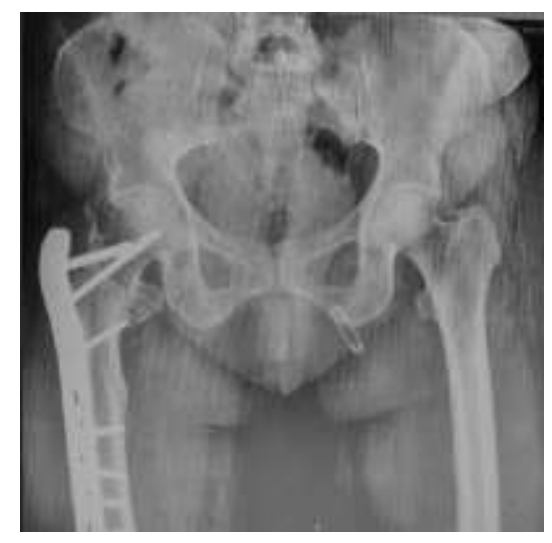

Figure 7: Case 5; X-ray at 4 months follow up shows union with good callus formation.
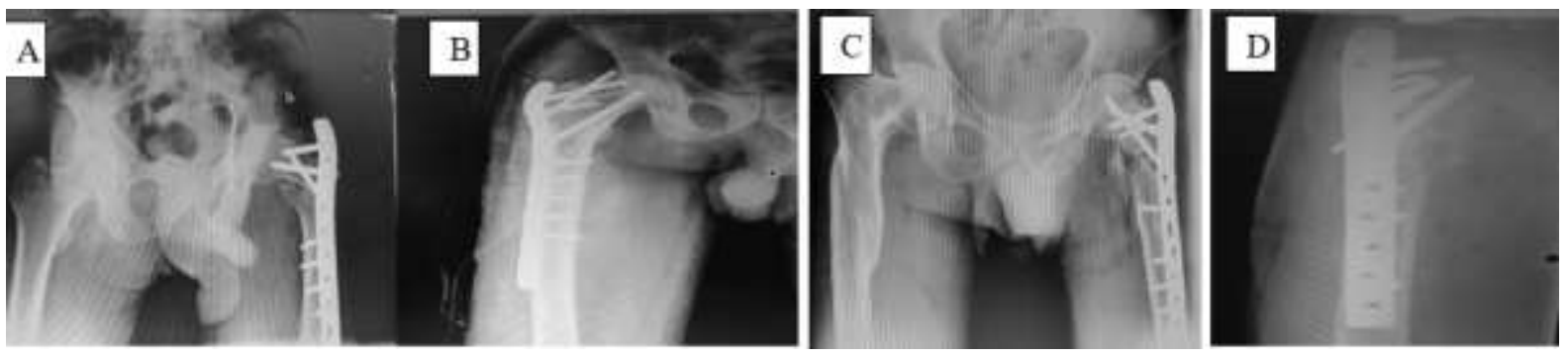

Figure 8: Complications; (A) varus collapse; (B) screw cut out; (C) non-union; (D) varus collapse.

Static and dynamic quadriceps strengthening exercises were started.

Drain was removed after 48 hours. Alternate followed by complete suture removal was done on day 14 .

\section{Follow up}

The patients were followed up according to the protocol and relevant data was collected at six weeks, three months, six months and nine months after operation with clinical and radiographic assessment for the progress of fracture healing and other complications. The functional outcome was assessed by Harris hip score. ${ }^{7}$

\section{RESULTS}

\section{Gender}

There was a male preponderance in the study. Male were $80 \%$ while females were $20 \%$ of the study population.

\section{Age}

Mean age in years was 59.04 years. There was a bimodal age distribution among young adults and older age group. Most of the cases belonged to the age group of more than 70 years.

\section{Side}

Right side was more commonly affected than left side. 
Table 1: Results.

\begin{tabular}{|lll|}
\hline Parameters & Range & Mean \pm SD \\
\hline Age (in years) & $32-95$ & $59.04 \pm 18.45$ \\
\hline Duration of surgery (in minutes) & $60-128$ & $86.23 \pm 19.52$ \\
\hline Blood loss (in ml) & $170-250$ & $207.5 \pm 26.51$ \\
\hline Hospital stay (in days) & $8-14$ & $10.53 \pm 2.04$ \\
\hline Harris hip score (in months) & & $69.46 \pm 6.30$ \\
\hline 1 & $52-76$ & $78.6 \pm 7.63$ \\
\hline 3 & $58-88$ & $87.6 \pm 7.83$ \\
\hline 9 & $64-96$ & $15.16 \pm 4.16$ \\
\hline Union time (in weeks) & $10-24$ & \\
\hline
\end{tabular}

\section{Mode of injury}

In young adults the most common mode of injury was high velocity trauma and in old age it was due to domestic fall.

\section{Fracture pattern}

The fractures were classified according to AO-OTA classification and most of the cases in our study belonged to $31 \mathrm{~A} 2-2(23.31 \%)$ followed by $31 \mathrm{~A} 2-1(16.66 \%)$.

\section{Duration of surgery}

The mean duration of surgery was found to be 86.23 minutes.

\section{Blood loss}

The average blood loss was $207.5 \mathrm{ml}$ of blood.

\section{Period of hospitalization}

The average period of hospitalization was found to be 10.53 days in our study.

\section{Complications}

Majority of the patients had no complications (83.31\%). Complications seen were superficial infection $(3.31 \%)$, varus collapse $(6.66 \%)$, screw cut-out $(3.31 \%)$ and nonunion $(3.31 \%)$.

\section{Clinical and functional evaluation}

The evaluation was done using the Harris hip score and $70 \%$ of patients had excellent outcomes, $16.66 \%$ patients had good outcome, $10 \%$ of patients had a fair outcome and only $3.31 \%$ of patients had a poor outcome. The mean Harris hip score at 1 month was 69.46, at 3 months was 78.6 and at 9 months was 87.6.

\section{Time for fracture union}

The average time required for fracture union in our study was 15.16 weeks.

\section{DISCUSSION}

Due to increase in longevity and road traffic accidents, the incidence of intertrochanteric fractures were increasing exponentially making it a growing concern for orthopedic surgeons worldwide. These fractures were known to occur in older individuals with co-morbidities which made the management of such fractures challenging. ${ }^{8,9}$

Fractures of the upper end femur made up for more than half of hip fractures in old age. ${ }^{10}$ A simple fall can result in such fractures in 6th-7th decade. We saw a bimodal distribution, in younger individuals it was due to road traffic accidents and in elderly it was due to simple fall and associated osteoporosis. ${ }^{11}$

Conservative management had a very limited role in the management of intertrochanteric fractures in the modern age due to associated problems of conservative management like bedsore, DVT, hypostatic pneumonia. ${ }^{12}$ The role of conservative management was only limited to patients who were medically unfit for surgery.

The fixation method ranged from dynamic hip screw (DHS) in stable fractures and intramedullary devices in unstable fractures which had some theoretical advantage over DHS because they didn't depend on the lateral cortex which was a problem in osteoporotic bones. The failure rates of these unstable fractures treated with DHS ranged from $6-30 \% .^{13-17}$ Fogagnolo et al found that the intraoperative technical and mechanical complication rate to be as high as $23.4 \% .{ }^{18}$ Uzun et al reported non-union $5.7 \%$, secondary varus displacement $25.7 \%$, screw cut-out $5.7 \%$, reverse $\mathrm{Z}$ effect $14.3 \% .^{19}$

Many internal fixation devices had been used in treatment of intertrochanteric fractures because of high incidence of complications reported after using these surgical implants. There was a lack of a satisfactory implant in the surgical treatment of intertrochanteric fractures which had led to a series of evolution in the development of a perfect implant.

The $5.0 \mathrm{~mm}$ proximal femoral locking compression plate was a limited contact, angular stable construct which was specifically designed for fractures in the proximal femoral region. ${ }^{20}$ The screw head locks into the PFLCP unlike 
conventional compression plate, thereby creating an angular, stable construct. ${ }^{21}$ Thus, the proximal femoral locking plate did not fail at screw bone interface and provided a strong anchor in osteoporotic bones. ${ }^{22,23}$ There were multiple locking screw holes in the plate and therefore various options were available to treat complex fractures. Close plate-to-bone contact was not needed and the PFLCP can also function as an internal external fixator which minimized the pressure on the periosteum enabling better biological healing. ${ }^{24,25}$

In the current study we attempted to study, evaluate, document and measure our efficiency in the management of intertrochanteric fractures using PFLCP. This study was conducted on a total of 30 patients with intertrochanteric fractures treated with PFLCP.

In the present study, the mean age was found to be $59.04 \pm 18.45$ years against $55.3 \pm 17.9$ years and 59.6 years according to Prabhat et al and Shah et al respectively. ${ }^{28,29}$ Our study also showed a bimodal distribution of patients. The first peak occurred in young age where patients had high velocity trauma and the second peak occurred in older age group where there was osteoporosis and a simple fall could result in a fracture.

The fracture pattern we most commonly encountered was 31A2-2 whereas Hodel et al and Lee et al found it to be $31 \mathrm{~B} 2$ and 29A2 respectively. ${ }^{26,32}$

In the present study, the mean operative time was found to be $86.23 \pm 19.52$ minutes while Agarwal et al and Lee et al found it to be 93 and 151.6 minutes respectively. ${ }^{26,27}$

The mean blood loss in our study was found to be $207.5 \pm 26.51 \mathrm{ml}$ as compared to $200 \mathrm{ml}$ in the study by Govindasamy et al. ${ }^{31}$ We measured the blood loss by mop counts, that is, each fully soaked mop containing $50 \mathrm{ml}$ of blood.

The mean hospital stay for patients included in our study was $10.53 \pm 2.04$ days against $8.19 \pm 2.04$ days in study by Agarwal et al. ${ }^{29}$

The complications that we found were that one patient $(3.31 \%)$ had superficial infection, two patients $(6.66 \%)$ had varus collapse, one patient $(3.31 \%)$ had screw cut-out and one patient $(3.31 \%)$ had non-union. The patients who had superficial infection were given prolonged antibiotics and the infection healed completely. Lee et al in his study mentioned that four patients $(15.3 \%)$ had loosening of screws, two patients $(7.69 \%)$ had delayed union and one patient $(3.84 \%)$ had deep infection. ${ }^{26}$ Agarwal et al in his study found that one patient $(3.84 \%)$ had non-union and two patients $(7.69 \%)$ had superficial infection. ${ }^{29}$

In the present study, we found the average Harris hip score at 3 months to be $69.46 \pm 6.30$, at 6 months to be $78.6 \pm 7.63$ and at 9 months to be $87.6 \pm 7.83$.
The average Harris hip score found in studies by Agarwal et al, Lee et al and Ibrahim et al was 88.4, 69.1 \pm 17.9 and 84.5 respectively. ${ }^{26,29,30}$ In our study, 21 patients $(70 \%)$ had excellent outcome, 5 patients $(16.66 \%)$ had good outcome, 3 patients $(10 \%)$ had fair outcome and 1 patient $(3.31 \%)$ had poor outcome.

We have used the radiological evidence of callus at the fracture site as the criteria of union. The mean time for fracture union was found to be $15.16 \pm 4.16$ weeks as compared to 18.04 weeks and 17 weeks in the study by Agarwal et al and Sasnur et al respectively. ${ }^{27,29}$

This study needed further evaluation with a larger number of patients and a longer follow up.

\section{CONCLUSION}

Intertrochanteric femur fractures are one of the most frequently encountered fractures by orthopedic surgeons all over the world.

Various fixation methods are available for treatment of intertrochanteric femur fractures which range from DHS to intramedullary devices but these are associated with many complications. PFLCP is a limited contact, angular stable construct unlike conventional plates. This plate also provides a strong anchor in osteoporotic bones.

A prospective study was carried out in 30 patients of radiologically confirmed intertrochanteric fractures. We made an attempt to study the efficacy of management as well as the rate of infection and complications in patients treated with PFLCP. Patients were regularly followed up and clinical and radiological assessment was done at successive visits. The data collected was analyzed and it was concluded that PFLCP is a good option for treating complex proximal femoral fractures especially those with poor bone stock with low complication rates. However, this needs further evaluation with a larger sample size.

Funding: No funding sources

Conflict of interest: None declared

Ethical approval: The study was approved by the institutional ethics committee

\section{REFERENCES}

1. Horowitz BG. Retrospective analysis of hip fractures. Surg Gynecol Obstet. 1966;123(3):565-70.

2. Boyd HB, Griffin LL. Classification and treatment of the trochanteric fractures. Arch Surg. 1949;58(6):853-66.

3. Evans EM. The treatment of trochanteric fractures of the femur. J Bone Joint Surg Br. 1949;31(2):190-203.

4. Koyuncu S, Altay T, Kayali C, Ozan F, Yamak K. Mechanical failures after fixation with proximal femoral nail and risk factors. Clin Interv Aging. 2015;10:1959-65.

5. Müller M, Seitz A, Besch L, Hilgert RE, Seekamp A. Proximal femur fractures: Results and complications 
after osteosynthesis with PFN and TGN. Unfallchirurg. 2008;111(2):71-7.

6. Uzun M, Ertürer E, Oztürk I, Akman S, Seçkin F, Ozçelik IB. Long term radiographic complications following treatment of unstable intertrochanteric femoral fractures with the proximal femoral nail and effects on functional results. Acta Orthop Traumatol Turc. 2009;43(6):457-63.

7. Harris H. Traumatic arthritis of the hip after dislocation and acetabular fractures: treatment by mold arthroplasty. An end-result study using a new method of result evaluation. J Bone Joint Surg Am. 1969;51(4):737-55.

8. Dean GL, David S, Jason HN. Osteoporotic pertrochateric fractures; management and concurrent controversies. J Bone Jt Surg (Am). 2004;72:737-52.

9. Kaufer H. Mechanics of the treatment of hip injuries. Clin Orthop Relat Res. 1980;(146):53-61.

10. Romanes GJ. Cunningham's manual of practical anatomy: upper and lower limb. 15th ed. New York: Oxford university press; 1986.

11. Jacobs RR, McClain O, Armstrong HJ. Internal fixation of intertrochanteric hip fractures. Clin Orthop Relat Res. 1980;(146):62-70.

12. Kulkarni GS. Treatment of trochanteric fractures of hip by modified Richards compression and collapsing screw. Indian J Orthoped. 1984;18(1):28.

13. Kyle RF, Gustillo RB, Premer RF. Analysis of six hundred and twenty two intertrochanteric hip fractures. J Bone Joint Surg Am. 1979;61(2):216-21.

14. Mariani E, Rand JA. Nonunion of intertrochanteric fractures of the femur following open reduction and internal fixation. Clin Orthop Relat Res. 1987;(218):81-9.

15. Haentjens P, Casteleyn PP, DeBoeck H, Handelberg F, Opdecam P. Treatment of unstable intertrochanteric and subtrochanteric fractures in elderly patients. J Bone Joint Surg Am. 1989;71(8):1214-25.

16. Gundle R, Gargan MF, Simpson HRW. How to minimize failure of fixation of unstable intertrochanteric fractures. Injury. 1995;26(9):611-4.

17. Simpson AHRW, Varty K, Dodd CA. Sliding hip screws: modes of failure CAF. Injury. 1989;20(4):227-31.

18. Fogagnolo F, Kfuri M, Paccola CAJ. Intramedullary fixation of pertrochanteric hip fractures with the short AO-ASIF proximal femoral nail. Arch Orthop Trauma Surg. 2004;124(1):31-7.

19. Grawe B, Le T, Williamson S, Archdeacon A, Zardiackas L. Fracture fixation with two locking screws versus three nonlocking screws: a biomechanical comparison in a normal and an osteoporotic bone model. Bone Joint Res. 2012;1(6):118-24.

20. Müller ME, Allgower M, Schneider R, Steinemann S, Straumann F, Weber BG. Technique of Internal Fixation of Fractures. 1st ed. Berlin: SpringerVerlag; 1991.
21. Wagner M. General principles for the clinical use of the LCP. Injury. 2003;34(2):31-42.

22. Freeman AL, Tornetta P, Schmidt A. How much do locked screws add to the fixation of "hybrid" plate constructs in osteoporotic bone? J Orthop Trauma. 2010;24(3):163-9.

23. Fan S, Yin M, Xu Y, Ren C, Ma T, Lu Y, Li M, Li Z, Zhang K. Locking compression plate fixation of femoral intertrochanteric fractures in patients with preexisting proximal femoral deformity: a retrospective study. J Orthop Surg Res. 2021;29;16(1):285

24. Gardner MJ, Helfet DL, Lorich DG. Has locked plating completely replaced conventional plating? Am J Orthop (Belle Mead NJ. 2004;33(9):439-46.

25. Fulkerson E, Egol KA, Kubiak EN, Liporace F, Kummer FJ, Koval KJ. Fixation of diaphyseal fractures with a segmental defect: a biomechanical comparison of locked and conventional plating techniques. J Trauma. 2006;60(4):830-5.

26. Lee WT, Murphy D, Kagda FH, Thambiah J. Proximal femoral locking compression plate for proximal femoral fractures. J Orthop Surg (Hong Kong). 2014;22(3):267-93.

27. Sasnur PA, Hathiwale I, Sasnur AH, Biradar K. Surgical outcome of proximal femoral fractures using proximal femoral-locking compression plate. Al Ameen J Med Sci. 2015;8(3):233-8.

28. Shah MD, Kapoor CS, Soni RJ, Patwa JJ, Golwala PP. Evaluation of outcome of proximal femur locking compression plate (PFLCP) in unstable proximal femur fractures. J Clin Orthop Trauma. 2017;8(4):288-92.

29. Agrawal P, Gaba S, Das S, Singh R, Kumar A, Yadav G. Dynamic hip screw versus proximal femur locking compression plate in intertrochanteric femur fractures (AO 29A1 and 29A2): a prospective randomized study. J Nat Sci Biol Med. 2017;8(1).

30. Ibrahim S, Meleppuram JJ. A retrospective analysis of surgically-treated complex proximal femur fractures with proximal femoral locking compression plate. Rev Bras Ortop. 2017;52(6):644-50.

31. Govindasamy R, Gnanasundaram R, Kasirajan S, Meleppuram JJ, Archit K. Proximal femur locking compression plate in complex proximal femoral fractures: a retrospective analysis. Int J Res Orthop. 2016;2(3):104-8.

32. Hodel S, Beeres FJP, Babst R, Link BC. Complications following proximal femoral locking compression plating in unstable proximal femur fractures: medium-term follow-up. Eur J Orthop Surg Traumatol. 2017;27(8):1117-24.

33. Gunadham U, Jampa J, Suntornsup S, Leewiriyaphun B. The outcome in early cases of treatment of subtrochanteric fractures with proximal femur locking compression plate. Malays Orthop J. 2014;8(2):22-6

Cite this article as: Lingayat MB, Rathod PP

Evaluation of functional outcome of

intertrochanteric femur fractures treated with proximal femoral locking compression plate. Int $\mathbf{J}$ Res Orthop 2021;7:919-25. 